ORIGINAL ARTICLE

\title{
Primary Anastomosis versus Colostomy in Patients with Penetrating Colonic Injuries; A Comparative Study
}

\author{
KHALID MAHMOOD ${ }^{1}$, ALLAH NAWAZ², AHMAD HASSAN KHAN ${ }^{3}$, ASAD RIZWAN RANA ${ }^{4}$, RAŻA FARRUKH $^{5}$, NAZIM \\ HAYAT 6 \\ ${ }^{1,2}$ Assistant Professor Surgery, Sargodha Medical College \\ ${ }^{3}$ Associate Professor Surgery Sargodha Medical College \\ ${ }^{4}$ Associate Professor Anaesthesia, Rai Medical College Sargodha \\ ${ }^{5}$ Assistant Professor Anaesthesia, Sargodha Medical College \\ ${ }^{6}$ Associate Professor Surgery, University Medical \&Dental College, Faisalabad \\ Corresponding author: Dr. Khalid Mahmood, E-mail.drkhalidmahmoodsgd@gmail.com, Cell No.+923006027673
}

\begin{abstract}
Background: Penetrating colon injuries treatment has been a controversial topic of discussion in medical literature. The literature shows that randomized trials comparing primary repair versus bypass showed no significant difference in complication rates between the two groups. While other trials comparing complication rates between the two groups showed that the primary repair has lower complication rates as compared to the colostomy.

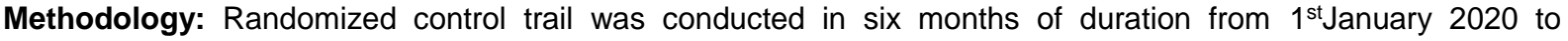

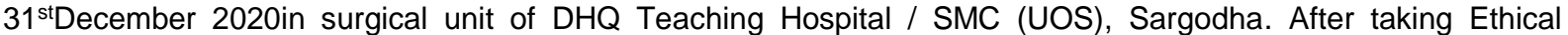
approval from the hospital, the study was conducted on 300 patients sample size calculated through open Epi sample size calculator with margin of error $5 \%$ and confidence interval $95 \%$. Randomized blotting technique was used for randomization to overcome biasness.

Results: Group 01 of primary anastomosis had 97 (64.67\%) males and 53 (35.33\%) females while group 02 of colostomy had 92 (66.34\%) males and 58 (33.66\%) females. complications intra-abdominal abscess was analyzed between both groups. In group 01 primary anastomosis, only $4(2.66 \%)$ patients develop intraabdominal abscess while in rest of patients i.e. 146(97.34\%) showed efficacy to primary anastomosis. In group 02 of colostomy, 27 (18\%) patients develop intra-abdominal abscess while rest of patients i.e. 123(82\%) patients showed efficacy towards colostomy.

Conclusion: In penetrating colon injuries, anastomosis showed more efficacy, safe to use and excellent results on the basis of post-operative complications as compared to colostomy.

Keywords: Primary anastomosis, defunctioning in colostomy, penetrating colonic injuries, effectiveness
\end{abstract}

\section{INTRODUCTION}

Penetrating colon injuries treatmenthas been a controversial topic of discussion in medical literature(1). In large majority of penetrating colon injuries that are either minor or moderately severe, primary repair has become the standard way of treatment(2).

In the past, a civil colon trauma was treated with a bypass colostomy. The primary repair was actively discouraged due to the perceived high risk of an anastomotic rupture. This was a direct result of the surgical experience during World War II, when the introduction of mandatory bypass colostomy dramatically reduced morbidity and mortality related to colon injury(3-5).Globally, penetrating abdominal trauma is increasing - in the US alone, penetrating injuries account for approximately $6 \%$ of hospital admissions and are the second most common mechanism for fatal injuries after vehicle-related injuries. The same accounts for at least $20 \%$ of all fatal injuries(6, $7)$. This incidence is almost the same around the world, but in underdeveloped countries affected by social and domestic violence, such as Pakistan, the number is higher than in others, and particularly of those affected. The large intestine is prone to injury in all of these cases due to its size and anatomical fixation $(8,9)$.

The literature shows that randomized trials comparing primary repair versus bypass showed no significant difference in complication rates between the two groups(6). While other trials comparing complication rates between the two groups showed that that the primary repair has lower complication rates compared to the colostomy $(7,10)$.

Previously accepted contraindications to primary repair like shock, peritonitis, concurrent kidney injury, and delay have been increasingly questioned. By the turn of the millennium, the Eastern Association for Trauma Surgery (EAST) guidelines proposed that there was enough high quality evidence to support a primary standard of repair for all non-destructive bowel injuries(11).

Despite the fact that anastomosis is more effective than colostomy, still in Pakistani set-up colostomy is more frequently used as compared to anastomosis. Aim of our study is to compare both methods and recommend anastomosis as standard procedure in colonic injuries. This study will also help in comparison of complications associated with both procedures.

\section{METHODOLOGY}

Randomized control trail was conducted in six months of duration from $1^{\text {st }}$ anuary 2020 to $31^{\text {st }}$ December 2020in surgical unit of DHQ Teaching Hospital / SMC (UOS), Sargodha. After taking Ethical approval from the hospital, the study was conducted on total of 300 patients sample size calculated through open Epi sample size calculator with margin of error 5\% and confidence interval 95\%. Randomized blotting technique was used for randomization to overcome biasness. Inclusion criteria for the study was patients of penetrating colonic injuries presented to surgical 
unit in 10 hours of injury of both genders, male and female having age in between 20 years to 50 years. Patients with operative BP level less than $90 \mathrm{mmHg}$, requiring more than 4 units of blood and having two or more associated organ injuries were excluded. Written informed consent was taken from the patients or patients' attendant after preliminary investigations- patients were randomly allocated into 2 groups, group 01 of primary anastomosis and group 02 of colostomy, according to the inclusion/exclusion criteria. Primary anastomosis was carried out using single layer intra mucosal interrupted technique with absorbable suture vicryle $3 / 0$. In group 02 patients, colostomy was done using vicryle $3 / 0$ for anchoring the bowl to the skin surface. Data was collected using pre-designed Performa. Data of demographics, operative findings and postoperative complications like intra-abdominal abscess and wound clearance was noted. The effectiveness was measured in terms of intra-abdominal collection for the accumulation of pus inside was observed in Peritoneal cavity confirmed by ultrasound and infection of the surgical site, in the case of infection of the laparotomy incision runs from erythema Even wound dehiscence was carefully observed.

Collected data was then analyzed using SPSS version 22. Data was analyzed and shown in tables and graph.

\section{RESULTS}

Patients were divided into two groups: group 01 of primary anastomosis and group 02 of colostomy. Each group contain 150 patients. Patients were divided into three groups on the basis of age. Group A contain patients from age 20 years to 30 years, group $B$ contain patients from age 31 to 40 years and group $C$ contain patients from 41 years to 50 years. Frequency, mean and standard deviation for each group was shown in table 01 .

Table 02: Frequency of Age group
\begin{tabular}{|l|l|l|}
\hline Age group & Group 01 Anastomisis & Group 02 Colostomy \\
\hline $21-30$ years & $42(28 \%)$ & $47(31.33 \%)$ \\
\hline $31-40$ years & $82(54.66 \%)$ & $84(56 \%)$ \\
\hline $41-50$ years & $26(17.34 \%)$ & $19(12.67 \%)$ \\
\hline MEAN \pm SD & $34 \pm 1.92$ & $33 \pm 1.87$ \\
\hline
\end{tabular}

On the basis of Gender, group 01 of primary anastomosis had $97(64.67 \%)$ males and $53(35.33 \%)$ females while group 02 of colostomy had 92 (66.34\%) males and $58(33.66 \%)$ females.

Graph 01: Gender Distribution

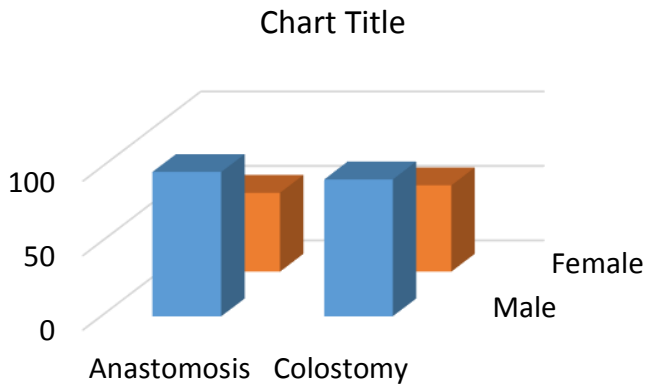

Male $\square$ Female
On the basis of complications intra-abdominal abscess were analyzed between both groups. In group 01 primary anastomosis, only $4(2.66 \%)$ patients develop intraabdominal abscess while in rest of patients i.e. $146(97.34 \%)$ showed efficacy to primary anastomosis. In group 02 of colostomy, 27 (18\%) patients develop intraabdominal abscess while rest of patients i.e. 123(82\%) patients showed efficacy towards colostomy.

Wound infection between two groups was analyzed and in group 01 of primary anastomosis 21 (14\%) patients had wound infection while 129 (86\%) patients were free from Wound infection. Whereas in group 02 of colostomy, $69(46 \%)$ patients had a wound infection while the remainder 81 (54\%) had no such infection.

Table 02: Distribution of Post-Op Complications:

\begin{tabular}{|l|l|l|l|l|}
\hline $\begin{array}{l}\text { Post-Op } \\
\text { Complication }\end{array}$ & \multicolumn{2}{|l|}{ Group 01 Anastomosis } & \multicolumn{2}{l|}{ Group 02 Colostomy } \\
\hline & Effective & Not effective & Effective & $\begin{array}{l}\text { Not } \\
\text { effective }\end{array}$ \\
\hline $\begin{array}{l}\text { Intra- } \\
\text { abdominal } \\
\text { abscess }\end{array}$ & $\begin{array}{l}146 \\
(97.34 \%)\end{array}$ & $4(2.66 \%)$ & $123(82 \%)$ & $27(18 \%)$ \\
\hline $\begin{array}{l}\text { Wound } \\
\text { Clearance }\end{array}$ & $\begin{array}{l}129 \\
(86 \%)\end{array}$ & $21(14 \%)$ & $81(54 \%)$ & $69(46 \%)$ \\
\hline
\end{tabular}

The overall effectiveness between the two groups was based on the intra-abdominal harvest and analyzed. The primary anastomosis was found to be effective in 146 $(97.34 \%)$ patients while the colostomy was performed effective in $123(82 \%)$ patients.

\section{DISCUSSION}

Abdominal trauma is the one of the major and leading cause of mortality and morbidity in first 40 years and the third leading cause of death in overall life. One of the study reported that the incidence of intra-abdominal abscess rate was $2.85 \%$ in the anastomotic group as compared to $10 \%$ in the colostomy group. Comparison on the basis of wound infection, the rate of wound infection was also lower in the anastomotic group as compared to colostomy group, that is $14.28 \%$ wound infection was in anastomosis group versus $40 \%$ in colostomy group showing the effectiveness of primary anastomosis that is similar this study results. The colostomy is no longer the standard Treatment option due to its post-operative complications and the need for a subsequent operation(10). Even The colostomy itself is a cause of morbidity due to penetrating injuries to the colon(12).

Approximately $6 \%$ of A\&E filings worldwide accounted for penetrating injuries. Penetrating injuries in our country are on the peak and rising and reasons for this rise are increased violence, interpersonal and community confrontations, robbery, and increased domestic violence as young men are more susceptible to gun injuries. Our study also reported similar kind of scenario(13). Colon is the most common abdominal organ injured worldwide(14). The treatment of penetrating injuries to the large intestine has long been controversial. Traditionally, they have been treated by primary colostomy, but primary anastomosis treatment has grown in popularity over the past 10 to 15 decades, although it was initially recommended only to select patients(15). In cases with significant blood loss, dirt, and left side colon lesions, it was not recommended 
Lesions of more than two viscera in addition to colon lesions(16).

However, recent research around the world has found that primary repair of traumatic colon injuries can be safely performed in almost all cases, including war injuries $(10,12$, 17). In a study conducted in approximately 115 patients over a period of 2 decades who concluded that in patients without a planned anterior hernia (HPV), the primary anastomosis was a better treatment technique, with results showing around $0 \%$ complications compared to $36 \%$ of complications caused by colostomy(15) as it has the advantage of avoiding colostomy, postoperative care of the colostomy, and re-hospitalization and reoperation in terms of costs and morbidity. In addition, lesions on the right side of the colon that require resections have been reported to work very well after iliocolic anastomosis(18). Repair is cheap. Individual perforations in the colon are routinely treated with a primary occlusion. However, it is recommended that multiple perforations requiring resection be anastomosed, mainly by one author. The only lesions that require a colostomy are rectal lesions or lesions involving the duodenal pancreatic complex or larger vessels with compromised blood supply or delayed surgery for more than 72 hours, or selected destructive lesions(19).

Anostamotic leak is most common and questionable post-operative complication in anastomosis and consequent cause of mortality. only $3 \%$ of patients developed leaks reported in our study, which is slightly less than other studies conducted, while postoperative wound infections are comparable to other studies(20, 21).

\section{CONCLUSION}

In penetrating colon injuries, anastomosis showed more efficacy, safe to use and excellent results on the basis of post-operative complications as compared to colostomy.

\section{REFERENCES}

1. Chappuis CW, Frey DJ, Dietzen CD, Panetta TP, Buechter $\mathrm{KJ}$, Cohn Jr I. Management of penetrating colon injuries. A prospective randomized trial. Annals of surgery. $1991 ; 213(5): 492$.

2. Demetriades D, Murray JA, Chan L, Ordoñez C, Bowley D, Nagy KK, et al. Penetrating Colon Injuries Requiring Resection: Diversion or Primary Anastomosis? An AAST Prospective Multicenter Study. Journal of Trauma and Acute Care Surgery. 2001;50(5).

3. Ogilvie W. Abdominal wounds in the western deset. Surg Gynecol Obstet. 1944;78:225-38.

4. General OotS. Care of the wounded in theaters of operation. Circular Letter. 1943(178).

5. Conrad JK, Ferry KM, Foreman ML, Gogel BM, Fisher TL, Livingston SA. Changing management trends in penetrating colon trauma. Diseases of the colon \& rectum. 2000;43(4):466-71.

6. Smith SR, Morris L, Spreadborough S, Al-Obaydi W, D'Auria $\mathrm{M}$, White $\mathrm{H}$, et al. Management of blunt splenic injury in a UK major trauma centre and predicting the failure of nonoperative management: a retrospective, cross-sectional study. European Journal of Trauma and Emergency Surgery. 2018;44(3):397-406.

7. Kamath AS, Iqbal CW, Sarr MG, Cullinane DC, Zietlow SP, Farley DR, et al. Colonoscopic splenic injuries: incidence and management. Journal of Gastrointestinal Surgery. 2009;13(12):2136.

8. Naeem BK, Perveen S, Naeem N, Ahmed T, Khan I, Khan I, et al. Visceral injuries in patients with blunt and penetrating abdominal trauma presenting to a tertiary care facility in Karachi, Pakistan. Cureus. 2018;10(11).

9. Merchea A, Dozois EJ, Wang JK, Larson DW. Anatomic mechanisms for splenic injury during colorectal surgery. Clinical Anatomy. 2012;25(2):212-7.

10. Masoomi H, Carmichael JC, Mills S, Ketana N, Dolich MO, Stamos MJ. Predictive factors of splenic injury in colorectal surgery: data from the Nationwide Inpatient Sample, 20062008. Archives of Surgery. 2012;147(4):324-9.

11. Govender M, Madiba T. Current management of large bowel injuries and factors influencing outcome. Injury. 2010;41(1):58-63.

12. Musa O, Ghildiyal J, Pandey MC. 6 year prospective clinical trial of primary repair versus diversion colostomy in colonic injury cases. Indian Journal of Surgery. 2010;72(4):308-11.

13. Störmann P, Gartner K, Wyen H, Lustenberger T, Marzi I, Wutzler S. Epidemiology and outcome of penetrating injuries in a Western European urban region. European journal of trauma and emergency surgery. 2016;42(6):663-9.

14. Ch TH, Tajammul N, Bhatti MA, Hanif S. Firearm injuries-a study of 110 cases. Annals of King Edward Medical University. 2005;11(4).

15. Manley NR, Sharpe JP, Lewis RH, Iltis MS, Chaudhuri R, Fabian TC, et al. Analysis of over 2 decades of colon injuries identifies optimal method of diversion: Does an end justify the means? Journal of Trauma and Acute Care Surgery. 2019;86(2):214-9.

16. Singer MA. Primary repair of penetrating colon injuries. Diseases of the colon \& rectum. 2002;45(12):1579-87.

17. Brown CV, Teixeira PG, Furay E, Sharpe JP, Musonza T, Holcomb J, et al. Contemporary management of rectal injuries at Level I trauma centers: The results of an American Association for the Surgery of Trauma multi-institutional study. Journal of Trauma and Acute Care Surgery. 2018;84(2):225-33.

18. Demetriades D, Murray JA, Chan L, Ordoñez C, Bowley D, Nagy KK, et al. Penetrating colon injuries requiring resection: diversion or primary anastomosis? An AAST prospective multicenter study. Journal of Trauma and Acute Care Surgery. 2001;50(5):765-75.

19. Hudolin T, Hudolin I. The role of primary repair for colonic injuries in wartime. British journal of surgery. 2005;92(5):643-7.

20. Nelson RL, Singer M. Primary repair for penetrating colon injuries. Cochrane Database of Systematic Reviews. 2003(3).

21. Mickevicius A, Klizaite J, Tamelis A, Saladzinskas Z, Pavalkis D. Penetrating colorectal trauma: index of severity and results of treatment. Medicina (Kaunas, Lithuania). 2003;39(6):562-9. 